\title{
Current patterns of water and beverage consumption among Mexican children and adolescents aged 1-18 years: analysis of the Mexican National Health and Nutrition Survey 2012
}

\author{
Carmen Piernas', Simon Barquera ${ }^{2}$ and Barry M Popkin ${ }^{1, *}$ \\ 'Department of Nutrition, Gillings School of Global Public Health, Carolina Population Center, University of North \\ Carolina at Chapel Hill, 123 West Franklin Street, Chapel Hill, NC 27516, USA: ${ }^{2}$ Nutrition and Health Research \\ Center, National Institute of Public Health, Cuernavaca, Mexico
}

Submitted 3 December 2013: Final revision received 10 April 2014: Accepted 15 April 2014: First published online 27 May 2014

\begin{abstract}
Objective: To evaluate patterns of water consumption from plain water, beverages and foods among Mexican children and adolescents and to compare actual patterns of total daily water intake with the Dietary Reference Intakes (DRI).

Design: We analysed one $24 \mathrm{~h}$ dietary recall from Mexican children and adolescents. We calculated intakes of total daily water and water from foods and from beverages. Actual total water intake per capita was subtracted from the DRI for water to calculate the shortfall.

Setting: Mexican National Health and Nutrition Survey in 2012.

Subjects: Mexican children and adolescents ( $n$ 6867) aged 1-18 years.

Results: Approximately $73 \%$ of children and adolescents aged 1-18 years reported drinking plain water. Beverages and plain water represented $65.5 \%$ and $26.5 \%$ of total daily water intake, respectively. Among 1-3-year-olds, the top three main sources of water were from foods, plain water and water from plain milk. Among 4-8- and 9-13-year-olds, the main sources were from foods, plain water and agua fresca (fruit water). Among 14-18-year-olds, the main sources of water were plain water, water from foods and soda. A higher proportion of 1-3-year-olds and 4-8-year-olds met the DRI for water (38\% and $29 \%$, respectively). Among 9-13-year-olds and 14-18-year-olds, 13-19\% of children met the DRI for water. Conclusions: Total daily water intakes remain below DRI levels in all age groups. Although plain water still contributes the greatest proportion to daily water intake among fluids, caloric beverages are currently major sources of water especially among older children and adolescents.
\end{abstract}

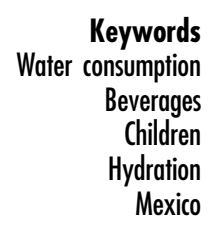

Water is a critical nutrient and its importance for the prevention of nutrition-related diseases has received attention recently because of the shift towards higher consumption of fluids as caloric beverages ${ }^{(1,2)}$. When consumed adequately, water has no side-effects and provides no energy, which makes it one of the most recommended options as a beverage among populations facing obesity and its related complications ${ }^{(3,4)}$. In Mexico, the lack of available potable water in households and schools coincides with the increased proliferation of caloric sweetened beverages such as soda and agua fresca (fruit water made in stalls or at home, usually with sugar added $)^{(5-7)}$. In this context, adequate hydration among children in Mexico has become a cause of public health concern ${ }^{(4,8)}$. Although previous studies have investigated patterns of beverage consumption in Mexican children ${ }^{(5,6)}$, to date no studies have focused on total daily water consumption from both food and beverage sources. This research is timely in Mexico as the recently passed $10 \%$ tax on beverages containing added sugar has been accompanied by a requirement that the government sets aside $80 \%$ of the revenue for obesity prevention and other policies to promote potable water consumption, particularly in elementary schools ${ }^{(9,10)}$.

Total daily water intake includes plain water (bottled or tap), water from other beverages and water from food sources (both intrinsic water in foods and water added in food preparations). Adequate Intakes (AI) for water are established using observed total water intakes in the population, desirable water volume per $4184 \mathrm{~kJ}$ (1000 kcal) and also desirable urine osmolality ${ }^{(8,11)}$. The Dietary Reference Intakes (DRI) for water and electrolytes reported by the US Institute of Medicine (IOM) established the AI for total daily water as between 1.3 and 1.7 litres/d in 1-3- and 4-8-year-olds and between $2 \cdot 1$ and $3 \cdot 3$ litres/d in 
9-13- and 14-18-year-olds. The desirable level of water per $4184 \mathrm{~kJ}(1000 \mathrm{kcal})$ is thought to be approximately 1-1.5 litres in children depending on activity levels and water losses ${ }^{(11,12)}$.

The present study investigated current patterns of water consumption from plain water, beverages and foods among Mexican children and adolescents by age group and gender. This analysis used dietary data from children and adolescents aged 1-18 years who participated in the Mexican National Health and Nutrition Survey 2012 (NHNS 2012). In addition, we compared actual patterns of total daily water intake with the DRI recommended by the US IOM.

\section{Methods}

\section{Survey design and sample: Mexican National Health and Nutrition Survey 2012}

We analysed dietary data from 6867 children and adolescents aged 1-18 years included in the NHNS 2012. The NHNS 2012 is a cross-sectional, probabilistic, populationbased survey with a multistage and stratified sampling, representative of Mexico ${ }^{(13)}$. The main objective of the NHNS 2012 was to characterize the health and nutritional status of the Mexican population. Information was collected from October 2011 to May 2012. The NHNS 2012 surveyed 50528 Mexican households within thirtyseven federal entities. The household response rate was $87 \%$. The NHNS 2012 sampling system included a proportional sample of both rural (population $<2500$ inhabitants) and urban (population $>2500$ inhabitants) areas that was drawn to be representative of four regional strata: (i) North (Baja California, Baja California Sur, Coahuila, Chihuahua, Durango, Nuevo León, Sonora and Tamaulipas);

(ii) Center (Aguascalientes, Colima, Estado de México, Guanajuato, Jalisco, Michoacán, Morelos, Nayarit, Querétaro, San Luis Potosí, Sinaloa and Zacatecas); (iii) Mexico City; and (iv) South (Campeche, Chiapas, Guerrero, Hidalgo, Oaxaca, Puebla, Quintana Roo, Tabasco, Tlaxcala, Veracruz and Yucatán). Additional detailed description of the sampling procedures and survey methodology can be found elsewhere ${ }^{(13)}$. The study was conducted according to the guidelines laid down in the Declaration of Helsinki and the survey protocol was revised and approved by the Ethics Committee of the Mexican National Institute of Public Health. Informed consent was obtained from each participant or participant's parent/guardian (assent was obtained for children aged $\geq 10$ years).

\section{Dietary intake data}

Dietary intake data were collected by trained interviewers using one $24 \mathrm{~h}$ recall in a stratified nationally representative sub-sample of the population, which captured approximately one-sixth of the total population. Respondents reported all foods and beverages consumed for the previous
$24 \mathrm{~h}$ period. This methodology is considered adequate to study the distribution of consumption of foods, energy and nutrients in population studies ${ }^{(14)}$. The main meal planner was asked to report dietary intake for children $<15$ years of age. For the NHNS 2012, an automated five-step multiplepass method was implemented to improve dietary recall. This multiple-step method is based on different probes that start asking for all foods and beverages consumed plus other typically forgotten foods, with a final probe for anything else that was consumed. During the interview, participants were asked to report consumption of foods, dishes (or preparations) and beverages, as well as the amount consumed, both purchased and food prepared at home. For foods prepared at home, participants were asked to report the detailed recipe. In addition, they were asked about food and beverages consumed between principal meals both inside and outside the home. Each interviewer was provided with a manual with photographs of commonly consumed foods, a food scale, measuring cups and serving spoons of various sizes to help in estimating the amount of food or beverages (in grams or millilitres) reported by each participant. In order to capture current changes in the Mexican food supply, we used the most recent food composition table, which was based on a combination of the chemical analyses conducted in Mexico on some unique foods and the food composition tables from the US Department of Agriculture's Food and Nutrient Database for Dietary Studies (FNDDS) ${ }^{(15,16)}$. Food composition tables capture macro- and micronutrients, water and fibre content in each food and beverage. The present analysis included all participants aged 1-18 years with complete dietary data.

\section{Beverage grouping system and category definition}

Beverages were grouped and classified using their food description or their energy density $(\mathrm{kJ} / \mathrm{kcal}$ per $100 \mathrm{ml})$. First, beverage ingredients that were recorded separately were combined into a single beverage group (e.g. if coffee, milk and sugar were recorded as part of a single preparation, we combined that information into a single group called 'coffee with milk and sugar'). We also aggregated some beverage groups that had similar nutritional or behavioural values. Most beverage groups were created using keyword searches at their food description. Sodas were further divided into 'caloric' and 'low calorie' versions using keyword searches (e.g. soda was classified as low calorie if the food description indicated that the beverage was 'light' or 'low calorie'). Other beverages such as coffee/tea with milk and/or sugar added were classified as 'low calorie' if they had less than $837 \mathrm{~kJ}$ $(20 \mathrm{kcal}) / 100 \mathrm{~g}$. Otherwise, they were classified as 'caloric'. Beverages were finally grouped into ten broad groups that represent all beverages consumed by the Mexican population: (i) water; (ii) agua fresca (fruit water made in stalls or at home, usually with sugar added); (iii) coffee/ tea; (iv) soda; (v) fruit \& vegetable juice; (vi) milk \& milk beverages; (vii) atole (corn-starch beverage); (viii) sports 
\& energy drinks; (ix) alcoholic beverages; and (x) other beverages (see online supplementary material, Supplemental Table 1).

\section{Socio-economic index and BMI}

The socio-economic index was generated by imputing deciles of income level to the households on the NHNS 2012, using demographic and socio-economic variables (i.e. characteristics of the head of the household, demographic household structure, home characteristics and appliances, household expenditure and level of marginalization of the geographic area), and based on the National Income and Expenditure Survey 2010 ${ }^{(17)}$. The socio-economic index was divided into tertiles and was used as a proxy for low, medium and high socio-economic status in the present study.

Participants' weight and height were measured by trained staff using a standardized protocol ${ }^{(13,18)}$. Weight and height were used to calculate standardized measures of BMI. To classify overweight and obesity we used the WHO criteria $^{(19,20)}$, which classified obesity as BMI > 3 SD above the WHO growth standard median and overweight as BMI $>2$ SD for children aged $<5$ years. For children and adolescents aged 5-18 years, obesity was defined as $\mathrm{BMI}>2 \mathrm{SD}$ and overweight as $\mathrm{BMI}>1 \mathrm{SD}$ above the WHO growth standard median.

\section{Statistical analysis}

All analyses were performed using the statistical software package Stata release 13 (2013). Survey commands were used to account for survey design and weighting to generate nationally representative results. Age was used to separate participants into different age groups: 1-3 years, 4-8 years, 9-13 years and 14-18 years. All analyses were performed for the entire sample and for each age and gender subpopulation.

To examine patterns of water and beverage consumption, we first calculated the mean total water intake (from foods and beverages); the mean water intake from all beverages and from plain water ( $\mathrm{ml} /$ capita per $\mathrm{d})$; and the percentage of consumers of plain water in the entire population and for each sociodemographic group. Then, we calculated the mean total volume of water that comes from each beverage group and the water volume from all foods ( $\mathrm{ml}$ of water/ capita per d). The proportion of volume of water that comes from each beverage type was calculated by dividing the mean total volume of water from each beverage type by the mean total volume of water intake per day. To investigate the contribution of foods and beverages to total daily energy intake $(\mathrm{kJ} / \mathrm{kcal})$, we calculated the mean daily per capita intake from all foods, all beverages and each beverage type. Using the IOM recommendations of water intake for each age and gender group, we calculated the total shortfall in water consumption, the proportion of children who met or failed to meet the DRI of water per day, and the mean of ratio of water to energy (litres/4184 kJ (1000 kcal)).
The mean of one $24 \mathrm{~h}$ recall should give a reasonable estimate of the mean intake at the population level, but might result in an over/underestimation of the proportion above or below a threshold value because it does not account for day-to-day variation in food consumption ${ }^{(14,21)}$. Then, the proportion of children and adolescents failing to meet the DRI for water might be overestimated. Estimates are presented as means with their standard errors. Statistically significant differences were tested using Student's $t$ test with the Bonferroni correction. A two-sided $P$ value of 0.05 was set to denote statistical significance.

\section{Results}

\section{Sociodemographic characteristics and water consumption patterns}

Water consumption patterns by sociodemographic group are shown in Table 1. Overall, intakes of total water, water from beverages and plain water were significantly higher among older compared with younger children and among males compared with females (Table 1). Approximately $73 \%$ of all children studied reported any consumption of plain water. Intakes of water were generally not significantly different between children in urban $v$. rural areas. There were a few differences between children in northern $v$. southern geographic areas and between higher $v$. lower socio-economic levels. Obese children and adolescents reported significantly higher amounts of total water, water from beverages and plain water compared with normal or overweight children.

\section{Patterns of water intake from food and beverage sources by age group}

Table 2 and Supplemental Table 2 show the main sources of water from all foods and different beverage types by age group among Mexican children and adolescents. Among 1-3-year-olds, the top three main sources of water were moisture in foods, plain water and water from plain milk. Among 4-8-and 9-13-year-olds, the main sources of water were moisture in foods, plain water and agua fresca (fruit water). Among 14-18-year-olds, the main sources of water were plain water, moisture in foods and soda.

Overall, beverages contributed about $65.5 \%$ of total daily water intakes in all children aged $1-18$ years, among which plain water contributed $26.5 \%$ of total daily water intake (Supplemental Table 2). Among beverages, plain water, agua fresca, caloric soda and plain high-fat milk provided the most daily water in all children. Although the proportion of water coming from all beverages and plain water was higher in older children, compared with younger children (1-4 years) the volume of water coming from caloric sweetened beverages such as soda and agua fresca was higher, whereas the proportion of water from milk and milk beverages was lower in older children and adolescents. 
Table 1 Demographic characteristics and consumption of water by sociodemographic group; children and adolescents aged 1-18 years ( $n$ 6867), Mexican National Health and Nutrition Survey, 2012

\begin{tabular}{|c|c|c|c|c|c|c|c|c|c|}
\hline & \multirow[b]{3}{*}{$n$} & \multirow[b]{3}{*}{$\%$} & \multicolumn{7}{|c|}{ Total water consumption $(\mathrm{ml} / \mathrm{d})$} \\
\hline & & & \multicolumn{2}{|c|}{$\begin{array}{l}\text { Water from foods } \\
\text { and beverages }\end{array}$} & \multicolumn{2}{|c|}{$\begin{array}{l}\text { Water from all } \\
\text { beverages }\end{array}$} & \multicolumn{3}{|c|}{ Plain water } \\
\hline & & & Mean & SE & Mean & $\mathrm{SE}$ & Mean & SE & $\%$ of consumers \\
\hline Total population & 6867 & 100 & $1613 \cdot 6$ & \multicolumn{5}{|c|}{ Gender } & $72 \cdot 7$ \\
\hline Male & 3477 & $50 \cdot 6$ & $1703 \cdot 6^{a}$ & $28 \cdot 8$ & $1133.0^{\mathrm{a}}$ & 23.6 & $460 \cdot 6^{\mathrm{a}}$ & $15 \cdot 4$ & $73 \cdot 5^{\mathrm{a}}$ \\
\hline Female & 3390 & $49 \cdot 4$ & $1521 \cdot 6^{\mathrm{b}}$ & $20 \cdot 9$ & $979.5^{\mathrm{b}}$ & $16 \cdot 3$ & $392 \cdot 8^{b}$ & $11 \cdot 7$ & $72 \cdot 0^{\mathrm{a}}$ \\
\hline \multicolumn{10}{|l|}{ Age group (years) } \\
\hline $1-3$ & 1623 & 14.7 & $1283.0^{\mathrm{a}}$ & 31.2 & $743.2^{\mathrm{a}}$ & 23.0 & $227.0^{\mathrm{a}}$ & 9.5 & $68 \cdot 7^{\mathrm{a}}$ \\
\hline $4-8$ & 2185 & 29.2 & $1426 \cdot 8^{b}$ & $25 \cdot 7$ & $922.1^{\mathrm{b}}$ & 21.5 & $350 \cdot 2^{b}$ & 13.2 & $72 \cdot 9^{\mathrm{a}, \mathrm{b}}$ \\
\hline $9-13$ & 1747 & 30.9 & $1658 \cdot 4^{\mathrm{c}}$ & $28 \cdot 3$ & $1061 \cdot 2^{c}$ & $20 \cdot 0$ & $426 \cdot 9^{c}$ & 14.7 & $72 \cdot 1^{a, b}$ \\
\hline 14-18 & 1312 & $25 \cdot 2$ & $1966 \cdot 5^{\mathrm{d}}$ & $51 \cdot 2$ & $1390 \cdot 3^{d}$ & 41.0 & $632 \cdot 2^{d}$ & $28 \cdot 0$ & $75 \cdot 6^{\mathrm{b}}$ \\
\hline \multicolumn{10}{|l|}{ Area } \\
\hline Urban & 4237 & 70.9 & $1605 \cdot 0^{\mathrm{a}}$ & 21.2 & $1064 \cdot 9^{a}$ & $17 \cdot 8$ & $428 \cdot 2^{a}$ & $12 \cdot 1$ & $71 \cdot 7^{\mathrm{a}}$ \\
\hline Rural & 2630 & $29 \cdot 1$ & $1634 \cdot 6^{\mathrm{a}}$ & $36 \cdot 7$ & $1038 \cdot 1^{a}$ & $25 \cdot 9$ & $424 \cdot 2^{a}$ & $15 \cdot 2$ & $75 \cdot 2^{\mathrm{b}}$ \\
\hline \multicolumn{10}{|l|}{ Geographic area } \\
\hline North & 1593 & $19 \cdot 0$ & $1542 \cdot 3^{\mathrm{a}}$ & 30.5 & $1034 \cdot 2^{\mathrm{a}, \mathrm{b}}$ & 23.9 & $415 \cdot 4^{\mathrm{a}}$ & 17.5 & $70 \cdot 4^{a}$ \\
\hline Central & 2521 & 31.5 & $1553 \cdot 4^{\mathrm{a}, \mathrm{b}}$ & 33.3 & $1009 \cdot 9^{a}$ & $24 \cdot 3$ & $422 \cdot 7^{\mathrm{a}}$ & $16 \cdot 6$ & $73 \cdot 4^{a}$ \\
\hline $\begin{array}{l}\text { Mexico City and metropolitan } \\
\text { area }\end{array}$ & 329 & $16 \cdot 2$ & $1730 \cdot 9^{a, b}$ & $66 \cdot 1$ & $1094 \cdot 0^{\mathrm{a}, \mathrm{b}}$ & $56 \cdot 5$ & $411 \cdot 0^{\mathrm{a}}$ & 33.9 & $69 \cdot 3^{a}$ \\
\hline South & 2424 & 33.3 & $1654 \cdot 1^{\mathrm{b}}$ & $26 \cdot 4$ & $1096 \cdot 8^{b}$ & 21.9 & $445 \cdot 7^{\mathrm{a}}$ & 14.7 & $75 \cdot 2^{a}$ \\
\hline \multicolumn{10}{|l|}{ Socio-economic level } \\
\hline Low & 2528 & 32.5 & $1574 \cdot 4^{\mathrm{a}}$ & 29.4 & $1004 \cdot 0^{\mathrm{a}}$ & $23 \cdot 3$ & $405 \cdot 3^{a}$ & 14.6 & $73 \cdot 5^{\mathrm{a}}$ \\
\hline Medium & 2447 & $34 \cdot 1$ & $1630 \cdot 0^{\mathrm{a}}$ & $37 \cdot 1$ & $1074 \cdot 8^{\mathrm{a}, \mathrm{b}}$ & $28 \cdot 6$ & $434 \cdot 0^{\mathrm{a}}$ & $16 \cdot 8$ & $72 \cdot 3^{a}$ \\
\hline High & 1892 & 33.4 & $1635 \cdot 0^{\mathrm{a}}$ & $30 \cdot 0$ & $1090 \cdot 6^{\mathrm{b}}$ & $25 \cdot 3$ & $441 \cdot 2^{\mathrm{a}}$ & $18 \cdot 3$ & $72 \cdot 5^{\mathrm{a}}$ \\
\hline \multicolumn{10}{|l|}{ BMI category } \\
\hline Normal & 5163 & $72 \cdot 5$ & $1580 \cdot 7^{a}$ & 21.3 & $1022 \cdot 7^{a}$ & $16 \cdot 9$ & $407 \cdot 9^{a}$ & $10 \cdot 3$ & $73 \cdot 0^{\mathrm{a}}$ \\
\hline Overweight & 1094 & $17 \cdot 7$ & $1635 \cdot 6^{a}$ & $40 \cdot 8$ & $1091 \cdot 5^{a}$ & 32.9 & $418 \cdot 7^{a}$ & 19.0 & $70 \cdot 6^{a}$ \\
\hline Obese & 610 & 9.8 & $1816 \cdot 5^{\mathrm{b}}$ & $60 \cdot 2$ & $1248 \cdot 6^{b}$ & $52 \cdot 3$ & $583 \cdot 3^{\mathrm{b}}$ & 45.5 & $74.4^{\mathrm{a}}$ \\
\hline
\end{tabular}

Estimates were weighted to adjust for unequal probability of sampling.

$\mathrm{a}, \mathrm{b}, \mathrm{c}, \mathrm{d}$ Statistical comparisons are made within each sociodemographic group. Mean estimates with unlike superscript letters were significantly different, Bonferroni-adjusted Student's $t$ test $(P<0.05)$.

\section{Patterns of water intake from food and beverage sources by gender and age group}

Analyses by gender were generally consistent with those performed by age with some differences between males and females (Fig. 1). Compared with females, males of any age had higher total daily water intakes, although these differences were significant only among 9-13-year-olds and 14-18-year-olds. Among 4-8-year-olds and 14-18-year-olds, intake of water from plain water was significantly higher in males compared with females. In addition, water intake from soda (caloric and low calorie) was significantly higher among 14-18-year-old males compared with females of the same age.

\section{Contribution of foods and beverages to total daily energy intake}

The contribution of different beverages and all foods to total daily energy intake is shown in Table $3(\mathrm{~kJ})$ and Supplemental Tables 3 (kcal) and 4 ( $\mathrm{g}$ or $\mathrm{ml})$. The top three sources of energy from beverages in all children aged 1-18 years were flavoured milk beverages, soda and plain high-fat milk. Older children and adolescents had significantly lower energy intakes from plain high- and low-fat milk but higher energy intake from caloric soda.

\section{Actual water intakes in relation to recommended intakes}

Patterns of total daily water intake were compared with the intakes recommended by the IOM for each age and gender group (Fig. 2). The shortfall in water consumption relative to the IOM recommendations was lower among younger children aged $1-3$ years and 4-8 years compared with those aged 9-13 years and 14-18 years of both genders. A higher proportion of 1-3-year-olds and 4-8-year-olds met the recommended intake of water (38\% and $29 \%$, respectively). Among 9-13-year-olds and 14-18-year-olds, 13-19\% of children met the daily water recommendations.

Figure 3 illustrates the mean ratio of water to energy (litres/per $4184 \mathrm{~kJ}(1000 \mathrm{kcal})$ ) by age and gender group. This ratio ranged between 0.82 and 0.98 litres/4184 kJ in the children studied. Younger children ( $1-3$ years old) had 0.98 litres $/ 4184 \mathrm{~kJ}$, which was the highest ratio of water per $4184 \mathrm{~kJ}$ among all age groups.

\section{Discussion}

Using nationally representative data on Mexican children and adolescents, we showed that, although plain water and moisture in foods still contribute the greatest proportion of 
Table 2 Volume of water $(\mathrm{ml} / \mathrm{d})$ from different beverage groups and water in foods consumed by age group; children and adolescents aged $1-18$ years $(n 6867)$, Mexican National Health and Nutrition Survey, 2012

\begin{tabular}{|c|c|c|c|c|c|c|c|c|c|c|c|c|}
\hline & \multicolumn{3}{|c|}{ Age $1-3$ years } & \multicolumn{3}{|c|}{ Age $4-8$ years } & \multicolumn{3}{|c|}{ Age $9-13$ years } & \multicolumn{3}{|c|}{ Age $14-18$ years } \\
\hline & \multicolumn{2}{|c|}{ Per capita $(\mathrm{ml} / \mathrm{d})$} & \multirow[b]{2}{*}{$\%$ of total } & \multicolumn{2}{|c|}{ Per capita $(\mathrm{ml} / \mathrm{d})$} & \multirow[b]{2}{*}{$\%$ of total } & \multicolumn{2}{|c|}{ Per capita $(\mathrm{ml} / \mathrm{d})$} & \multirow[b]{2}{*}{$\%$ of total } & \multicolumn{2}{|c|}{ Per capita $(\mathrm{ml} / \mathrm{d})$} & \multirow[b]{2}{*}{$\%$ of total } \\
\hline & Mean & SE & & Mean & $\mathrm{SE}$ & & Mean & $\mathrm{SE}$ & & Mean & SE & \\
\hline Total daily water & $1283 \cdot 0^{\mathrm{a}}$ & $31 \cdot 2$ & 100 & $1426 \cdot 8^{b}$ & $25 \cdot 7$ & 100 & $1658 \cdot 4^{c}$ & $28 \cdot 3$ & 100 & $1966 \cdot 5^{d}$ & $51 \cdot 2$ & 100 \\
\hline Water from foods & $539 \cdot 8^{a, b}$ & 22.6 & $42 \cdot 1$ & $504 \cdot 8^{\mathrm{a}}$ & 11.6 & 35.4 & $597 \cdot 2^{\mathrm{b}}$ & $16 \cdot 5$ & 36.0 & $576 \cdot 2^{\mathrm{b}}$ & 22.5 & 29.3 \\
\hline Water from beverages $\dagger$ & $743 \cdot 2^{\mathrm{a}}$ & 23.0 & 57.9 & $922 \cdot 1^{\mathrm{b}}$ & 21.5 & 64.6 & $1061 \cdot 2^{\mathrm{C}}$ & $20 \cdot 0$ & $64 \cdot 0$ & $1390 \cdot 3^{d}$ & 41.0 & $70 \cdot 7$ \\
\hline \multicolumn{13}{|l|}{ Water } \\
\hline Plain & $227.0^{\mathrm{a}}$ & 9.5 & $17 \cdot 7$ & $350.2^{\mathrm{b}}$ & $13 \cdot 2$ & 24.5 & $426 \cdot 9^{c}$ & 14.7 & $25 \cdot 7$ & $632 \cdot 2^{d}$ & 28.0 & $32 \cdot 2$ \\
\hline Flavoured/caloric & $7 \cdot 3^{\mathrm{a}}$ & $2 \cdot 3$ & 0.6 & $19 \cdot 4^{a, b}$ & 4.2 & 1.4 & $15 \cdot 1^{a, b}$ & 2.5 & 0.9 & $24 \cdot 9^{b}$ & 5.6 & 1.3 \\
\hline Agua fresca (fruit water) & $55 \cdot 7^{\mathrm{a}}$ & $6 \cdot 0$ & 4.3 & $125 \cdot 5^{\mathrm{b}}$ & $10 \cdot 1$ & 8.8 & $142 \cdot 9^{\mathrm{b}}$ & 11.6 & 8.6 & $120 \cdot 3^{\mathrm{b}}$ & 14.4 & $6 \cdot 1$ \\
\hline \multicolumn{13}{|l|}{ Coffee/tea } \\
\hline Caloric & $27.4^{\mathrm{a}}$ & 2.6 & $2 \cdot 1$ & $39.1^{\mathrm{b}}$ & 3.3 & $2 \cdot 7$ & $59.2^{\mathrm{c}}$ & $4 \cdot 8$ & 3.6 & $74.4^{\mathrm{C}}$ & $6 \cdot 4$ & 3.8 \\
\hline Plain/low calorie & $40 \cdot 4^{\mathrm{a}}$ & $17 \cdot 5$ & 3.1 & $35 \cdot 1^{a}$ & 4.0 & 2.5 & $44 \cdot 0^{\mathrm{a}}$ & $5 \cdot 3$ & $2 \cdot 7$ & $38 \cdot 5^{\mathrm{a}}$ & $4 \cdot 3$ & $2 \cdot 0$ \\
\hline \multicolumn{13}{|l|}{ Soda } \\
\hline Caloric & $28.9^{\mathrm{a}}$ & $2 \cdot 0$ & $2 \cdot 3$ & $62 \cdot 7^{\mathrm{b}}$ & 4.0 & 4.4 & $115 \cdot 6^{\mathrm{c}}$ & $6 \cdot 2$ & $7 \cdot 0$ & $216 \cdot 4^{d}$ & 11.9 & $11 \cdot 0$ \\
\hline Low calorie & $7 \cdot 2^{\mathrm{a}}$ & $1 \cdot 1$ & 0.6 & $24 \cdot 2^{a, b}$ & 7.8 & 1.7 & $26 \cdot 9^{b}$ & $7 \cdot 0$ & 1.6 & $37.5^{\mathrm{b}}$ & 6.5 & 1.9 \\
\hline \multicolumn{13}{|l|}{ Fruit \& vegetable juice } \\
\hline $100 \%$ natural juice & $7 \cdot 6^{\mathrm{a}}$ & 1.9 & 0.6 & $6 \cdot 6^{\mathrm{a}}$ & 1.1 & 0.5 & $7 \cdot 1^{\mathrm{a}}$ & 1.6 & 0.4 & $16 \cdot 5^{\mathrm{a}}$ & 5.9 & 0.8 \\
\hline Fruit/vegetable drinks & $49 \cdot 5^{\mathrm{a}}$ & 4.5 & 3.9 & $51 \cdot 1^{a}$ & 3.8 & 3.6 & $37.4^{\mathrm{a}}$ & 3.7 & $2 \cdot 3$ & $54.8^{\mathrm{a}}$ & $9 \cdot 2$ & $2 \cdot 8$ \\
\hline \multicolumn{13}{|l|}{ Milk \& milk beverages } \\
\hline Plain, high fat & $145 \cdot 8^{\mathrm{a}}$ & $8 \cdot 1$ & 11.4 & $79.1^{\mathrm{b}}$ & 5.5 & 5.5 & $66 \cdot 2^{\mathrm{b}}$ & $5 \cdot 0$ & 4.0 & $46 \cdot 8^{\mathrm{c}}$ & 4.8 & $2 \cdot 4$ \\
\hline Plain, low fat & $13 \cdot 4^{\mathrm{a}}$ & $3 \cdot 8$ & 1.0 & $8.5^{\mathrm{a}}$ & 1.9 & 0.6 & $3 \cdot 6^{a, b}$ & 1.1 & 0.2 & $2 \cdot 2^{\mathrm{b}}$ & 0.8 & 0.1 \\
\hline Milk beverages, flavoured & $81 \cdot 3^{\mathrm{a}}$ & $9 \cdot 6$ & $6 \cdot 3$ & $70 \cdot 3^{\mathrm{a}}$ & 4.7 & 4.9 & $69 \cdot 8^{\mathrm{a}, \mathrm{b}}$ & $8 \cdot 1$ & $4 \cdot 2$ & $50 \cdot 3^{\mathrm{b}}$ & $5 \cdot 1$ & $2 \cdot 6$ \\
\hline Milk with cereal & $16 \cdot 5^{\mathrm{a}}$ & $2 \cdot 0$ & 1.3 & $24 \cdot 1^{a}$ & $2 \cdot 4$ & $1 \cdot 7$ & $17 \cdot 5^{\mathrm{a}}$ & $2 \cdot 2$ & $1 \cdot 1$ & $20.8^{\mathrm{a}}$ & $2 \cdot 8$ & $1 \cdot 1$ \\
\hline \multicolumn{13}{|l|}{ Atole } \\
\hline Milk base & $19 \cdot 2^{\mathrm{a}}$ & 5.4 & 1.5 & $7 \cdot 9^{\mathrm{a}}$ & $1 \cdot 2$ & 0.6 & $11 \cdot 7^{\mathrm{a}}$ & 1.7 & 0.7 & $6 \cdot 6^{\mathrm{a}}$ & 1.3 & 0.3 \\
\hline Water base & $8 \cdot 4^{\mathrm{a}}$ & 1.6 & 0.7 & $10 \cdot 9^{\mathrm{a}}$ & 1.7 & 0.8 & $11.9^{\mathrm{a}}$ & $2 \cdot 3$ & 0.7 & $8 \cdot 3^{\mathrm{a}}$ & $2 \cdot 2$ & 0.4 \\
\hline Sports \& energy drinks & $1 \cdot 6^{\mathrm{a}}$ & 0.8 & $0 \cdot 1$ & $3 \cdot 4^{\mathrm{a}}$ & 1.5 & 0.2 & $2 \cdot 5^{\mathrm{a}}$ & 1.3 & 0.1 & $4 \cdot 0^{\mathrm{a}}$ & $2 \cdot 2$ & 0.2 \\
\hline Alcoholic beverages & - & - & - & - & - & - & $0.7^{\mathrm{a}}$ & 0.7 & 0.0 & $30.0^{\mathrm{b}}$ & $9 \cdot 7$ & 1.5 \\
\hline Other beverages & $6 \cdot 1^{\mathrm{a}}$ & 1.3 & 0.5 & $4 \cdot 1^{a, b}$ & 0.6 & 0.3 & $2 \cdot 1^{\mathrm{b}}$ & 0.6 & 0.1 & $5 \cdot 8^{a, b}$ & $2 \cdot 3$ & 0.3 \\
\hline
\end{tabular}

tIncludes plain water.

a,b,c,d Statistical comparisons are made between age groups. Mean estimates within a row with unlike superscript letters were significantly different, Bonferroniadjusted Student's $t$ test $(P<0.05)$.

total daily water, caloric sweetened beverages such as soda and agua fresca are currently major sources of water especially among older children and adolescents. Plain water was the main source of total daily water in all age groups. Intakes of total daily water, water from beverages and plain water were higher among older compared with younger children and among males compared with females. Younger children aged 1-3 years obtained more water from milk and milk beverages, whereas 4-8- and 9-13-year-olds had a higher proportion of water from agua fresca and 14-18-year-olds had a higher proportion of water from caloric soda. There was a significantly higher volume of water coming from soda in 14-18-year-olds males compared with females. A recent study in American children aged 4-8 years and 9-13 years using the US National Health and Nutrition Examination Surveys 20052010 showed that approximately $72 \%$ of children reported any amount of plain water (bottled or tap) ${ }^{(22)}$. The main sources of water in US children were plain water, milk and fruit drinks among 4-8-year-olds; and plain water, milk and soda among 9-13-year-olds. As in Mexican children, total daily water intake in US children was at belowrecommended levels. Other Mexican studies focusing on beverage consumption patterns in children aged 1-4 and 5-11 years and adolescents aged $12-18$ years showed large increases in caloric beverages from 1999 to 2006. The major beverage contributors to total energy intake in 2006 among Mexican children and adolescents were high-fat milk, fruit juice (with water/sugars added, including agua fresca) and carbonated and non-carbonated sweetened soda ${ }^{(5,6)}$. Consistent with our results, these previous studies found that younger children had a higher proportion of energy from milk whereas older children and adolescents moved towards more caloric sweetened beverages.

In relation to the IOM DRI, total daily water intakes in all age groups remained below AI levels and most children included in our study ( $\geq 81 \%$ ) failed to meet the IOM DRI for total daily water. Children aged 1-3 years had the smallest shortfall in total water and the greatest proportion that met the DRI for total water (38\%). On the other hand, although 14-18-year-old adolescents obtained a higher proportion of water from plain water than other age groups, their shortfall in total daily water was the highest because the AI for water increases with age ${ }^{(12)}$. Another criterion of adequate hydration is the volume of water per $4184 \mathrm{~kJ}$ (1000 kcal), with desirable values ranging from 1 to 1.5 litres. Only 1-3-year-old children approximated the desirable water:energy ratio with 0.98 litres $/ 4184 \mathrm{~kJ}$. Children aged 4-8 years and 9-13 years of both genders had the lowest water:energy ratios. Similarly, in the US study only $25 \%$ of $4-8$-year-olds, $15 \%$ of $9-13$-year-old males and $17 \%$ of $9-13$-year-old females met the IOM 


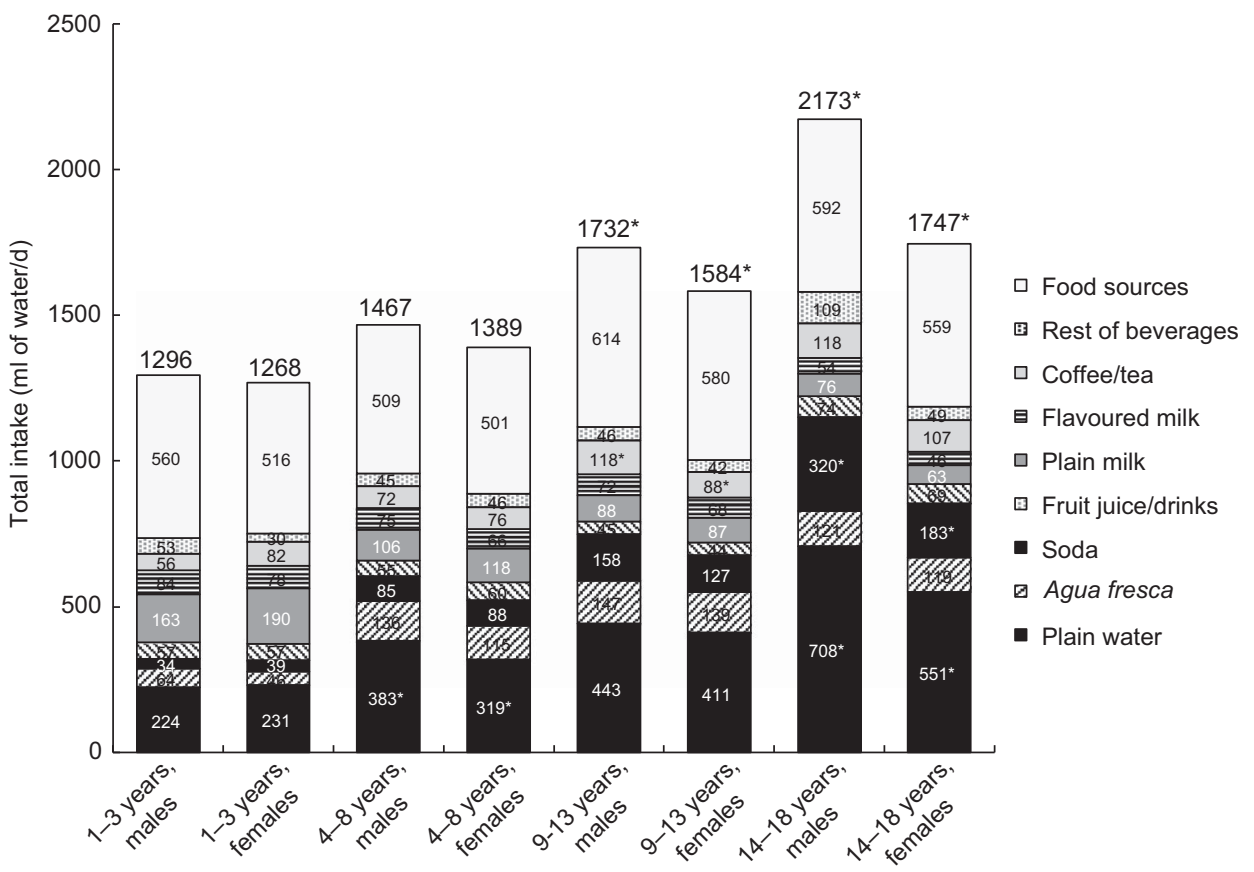

Fig. 1 Total daily water intake from all sources by age group and gender; children and adolescents aged 1-18 years ( $n$ 6867), Mexican National Health and Nutrition Survey, 2012. 'Rest of beverages' are flavoured water, milk-/water-based atole, sports \& energy drinks, alcoholic beverages, meal replacements, chocolate water and Yakult; 'coffee/tea' includes caloric and plain/lowcalorie coffee/tea; 'plain milk' includes high-fat and low-fat milk and milk added to cereal; 'soda' includes regular and diet soda. Comparisons are made between males and females for each age and beverage group; * indicates a significant difference between males and females, Bonferroni-adjusted Student's $t$ test, $P<0.05$

Table 3 Contribution of foods and beverages to total energy intake $(\mathrm{kJ} / \mathrm{d})$ consumed by age group; children and adolescents aged 1-18 years ( $n$ 6867), Mexican National Health and Nutrition Survey (NHNS), 2012

\begin{tabular}{|c|c|c|c|c|c|c|c|c|c|c|c|c|}
\hline & \multicolumn{3}{|c|}{ Age $1-3$ years } & \multicolumn{3}{|c|}{ Age $4-8$ years } & \multicolumn{3}{|c|}{ Age $9-13$ years } & \multicolumn{3}{|c|}{ Age $14-18$ years } \\
\hline & \multicolumn{2}{|c|}{ Per capita $(\mathrm{kJ} / \mathrm{d})$} & \multirow[b]{2}{*}{$\%$ of total } & \multicolumn{2}{|c|}{ Per capita $(\mathrm{kJ} / \mathrm{d})$} & \multirow[b]{2}{*}{$\%$ of total } & \multicolumn{2}{|c|}{ Per capita $(\mathrm{kJ} / \mathrm{d})$} & \multirow[b]{2}{*}{$\%$ of total } & \multicolumn{2}{|c|}{ Per capita (kJ/d) } & \multirow[b]{2}{*}{$\%$ of total } \\
\hline & Mean & SE & & Mean & SE & & Mean & $\mathrm{SE}$ & & Mean & $\mathrm{SE}$ & \\
\hline Total daily energy (kJ) & $5464 \cdot 3^{a}$ & 98.2 & 100 & $7086 \cdot 4^{\mathrm{b}}$ & $96 \cdot 9$ & 100 & $8356.0^{\mathrm{C}}$ & 129.9 & 100 & $9069.8^{d}$ & 195.6 & 100 \\
\hline Energy from foods & $4075 \cdot 3^{\mathrm{a}}$ & 92.1 & 74.6 & $5681 \cdot 8^{\mathrm{b}}$ & $86 \cdot 0$ & $80 \cdot 2$ & $6890 \cdot 3^{\mathrm{c}}$ & 121.8 & 82.5 & $7330 \cdot 8^{\mathrm{c}}$ & 170.9 & 80.8 \\
\hline Energy from beverages & $1389.0^{\mathrm{a}}$ & 52.7 & $25 \cdot 4$ & $1404 \cdot 6^{\mathrm{a}}$ & 34.3 & $19 \cdot 8$ & $1465 \cdot 7^{\mathrm{a}}$ & 37.9 & 17.5 & $1739.0^{\mathrm{b}}$ & 62.9 & $19 \cdot 2$ \\
\hline \multicolumn{13}{|l|}{ Water } \\
\hline Plain & - & - & - & - & - & - & - & - & - & - & - & - \\
\hline Flavoured/caloric & $8 \cdot 7^{\mathrm{a}}$ & 2.6 & 0.2 & $23.5^{\mathrm{b}}$ & $4 \cdot 8$ & 0.3 & $19 \cdot 7^{\mathrm{a}, \mathrm{b}}$ & 3.8 & 0.2 & $29 \cdot 8^{\mathrm{b}}$ & $6 \cdot 8$ & 0.3 \\
\hline Agua fresca (fruit water) & $109 \cdot 1^{\mathrm{a}}$ & $22 \cdot 3$ & $2 \cdot 0$ & $191.4^{\mathrm{b}}$ & $19 \cdot 7$ & $2 \cdot 7$ & $194 \cdot 4^{\mathrm{b}}$ & $16 \cdot 0$ & $2 \cdot \overline{3}$ & $188 \cdot 5^{\mathrm{a}, \mathrm{b}}$ & $26 \cdot 4$ & $2 \cdot 1$ \\
\hline \multicolumn{13}{|l|}{ Coffee/tea } \\
\hline Caloric & $128 \cdot 2^{a, b}$ & 21.4 & $2 \cdot 3$ & $131 \cdot 3^{\mathrm{a}}$ & $13 \cdot 9$ & 1.9 & $151 \cdot 7^{\mathrm{a}, \mathrm{b}}$ & $14 \cdot 1$ & 1.8 & $197.4^{\mathrm{b}}$ & 20.5 & $2 \cdot 2$ \\
\hline Plain/low calorie & $9 \cdot 3^{\mathrm{a}}$ & 1.5 & 0.2 & $15 \cdot 3^{\mathrm{a}, \mathrm{b}}$ & $2 \cdot 1$ & 0.2 & $16 \cdot 7^{\mathrm{b}}$ & 2.1 & 0.2 & $16 \cdot 0^{\mathrm{b}}$ & 1.9 & 0.2 \\
\hline \multicolumn{13}{|l|}{ Soda } \\
\hline Caloric & $58.9^{\mathrm{a}}$ & 4.1 & $1 \cdot 1$ & $126 \cdot 9^{b}$ & $8 \cdot 1$ & 1.8 & $235 \cdot 6^{c}$ & $12 \cdot 6$ & $2 \cdot 8$ & $443 \cdot 9^{d}$ & 24.5 & 4.9 \\
\hline Low calorie & $1 \cdot 2^{\mathrm{a}}$ & 0.4 & 0.0 & $3.9^{\mathrm{a}}$ & 1.6 & 0.1 & $3 \cdot 2^{\mathrm{a}}$ & $1 \cdot 2$ & 0.0 & $3.5^{\mathrm{a}}$ & 2.3 & 0.0 \\
\hline \multicolumn{13}{|l|}{ Fruit \& vegetable juice } \\
\hline $100 \%$ natural juice & $13 \cdot 7^{\mathrm{a}}$ & 3.2 & 0.3 & $12 \cdot 7^{\mathrm{a}}$ & $2 \cdot 2$ & 0.2 & $15 \cdot 5^{\mathrm{a}}$ & 3.6 & 0.2 & $34.4^{\mathrm{a}}$ & 12.6 & 0.4 \\
\hline Fruit/vegetable drinks & $105 \cdot 3^{\mathrm{a}}$ & 9.0 & 1.9 & $108 \cdot 4^{\mathrm{a}}$ & 7.9 & 1.5 & $81.5^{\mathrm{a}}$ & $7 \cdot 6$ & 1.0 & $117 \cdot 6^{\mathrm{a}}$ & $18 \cdot 2$ & 1.3 \\
\hline \multicolumn{13}{|l|}{ Milk \& milk beverages } \\
\hline Plain, high fat & $399.5^{\mathrm{a}}$ & 22.7 & $7 \cdot 3$ & $217.9^{b}$ & $15 \cdot 5$ & $3 \cdot 1$ & $186 \cdot 3^{\mathrm{b}}$ & $14 \cdot 3$ & $2 \cdot 2$ & $127 \cdot 6^{\mathrm{c}}$ & $13 \cdot 2$ & 1.4 \\
\hline Plain, low fat & $25.0^{\mathrm{a}}$ & 7.6 & 0.5 & $19 \cdot 1^{\mathrm{a}}$ & 4.5 & 0.3 & $7 \cdot 3^{\mathrm{a}, \mathrm{b}}$ & 2.0 & 0.1 & $4 \cdot 4^{\mathrm{b}}$ & 1.5 & 0.0 \\
\hline Milk beverages, flavoured & $311 \cdot 7^{\mathrm{a}}$ & 33.8 & 5.7 & $286 \cdot 4^{\mathrm{a}}$ & 17.9 & 4.0 & $290 \cdot 2^{\mathrm{a}}$ & $26 \cdot 7$ & 3.5 & $233.5^{\mathrm{a}}$ & 27.7 & 2.6 \\
\hline Milk with cereal & $98 \cdot 1^{\mathrm{a}}$ & $12 \cdot 6$ & 1.8 & $159 \cdot 9^{b}$ & $16 \cdot 1$ & 2.3 & $130 \cdot 9^{\mathrm{a}, \mathrm{b}}$ & $19 \cdot 9$ & 1.6 & $145 \cdot 9^{\mathrm{a}, \mathrm{b}}$ & 21.5 & 1.6 \\
\hline \multicolumn{13}{|l|}{ Atole } \\
\hline Milk base & $70 \cdot 9^{a, b}$ & 14.0 & 1.3 & $58 \cdot 2^{a, b}$ & $9 \cdot 3$ & 0.8 & $83.9^{\mathrm{b}}$ & $12 \cdot 6$ & 1.0 & $40 \cdot 3^{a}$ & 8.0 & 0.4 \\
\hline Water base & $25 \cdot 1^{\mathrm{a}}$ & 5.7 & 0.5 & $32 \cdot 6^{a}$ & 6.2 & 0.5 & $39 \cdot 3^{\mathrm{a}}$ & 7.3 & 0.5 & $41 \cdot 3^{\mathrm{a}}$ & 14.7 & 0.5 \\
\hline Sports \& energy drinks & $1.6^{\mathrm{a}}$ & 0.9 & 0.0 & $3 \cdot 8^{\mathrm{a}}$ & 1.7 & 0.1 & $2 \cdot 8^{\mathrm{a}}$ & 1.4 & 0.0 & $4.8^{\mathrm{a}}$ & 2.4 & 0.1 \\
\hline Alcoholic beverages & - & - & - & $0.0^{\mathrm{a}}$ & 0.0 & 0.0 & $0.9^{\mathrm{a}}$ & 0.9 & 0.0 & $72 \cdot 7^{b}$ & $21 \cdot 1$ & 0.8 \\
\hline Other beverages & $22 \cdot 6^{\mathrm{a}}$ & $5 \cdot 0$ & 0.4 & $13 \cdot 2^{\mathrm{a}}$ & 2.0 & 0.2 & $5 \cdot 9^{\mathrm{b}}$ & 1.6 & 0.1 & $37 \cdot 6^{a, b}$ & 17.9 & 0.4 \\
\hline
\end{tabular}

$\overline{a, b, c, d}$ Statistical comparisons are made between age groups. Mean estimates within a row with unlike superscript letters were significantly different, Bonferroniadjusted Student's $t$ test $(P<0.05)$. 


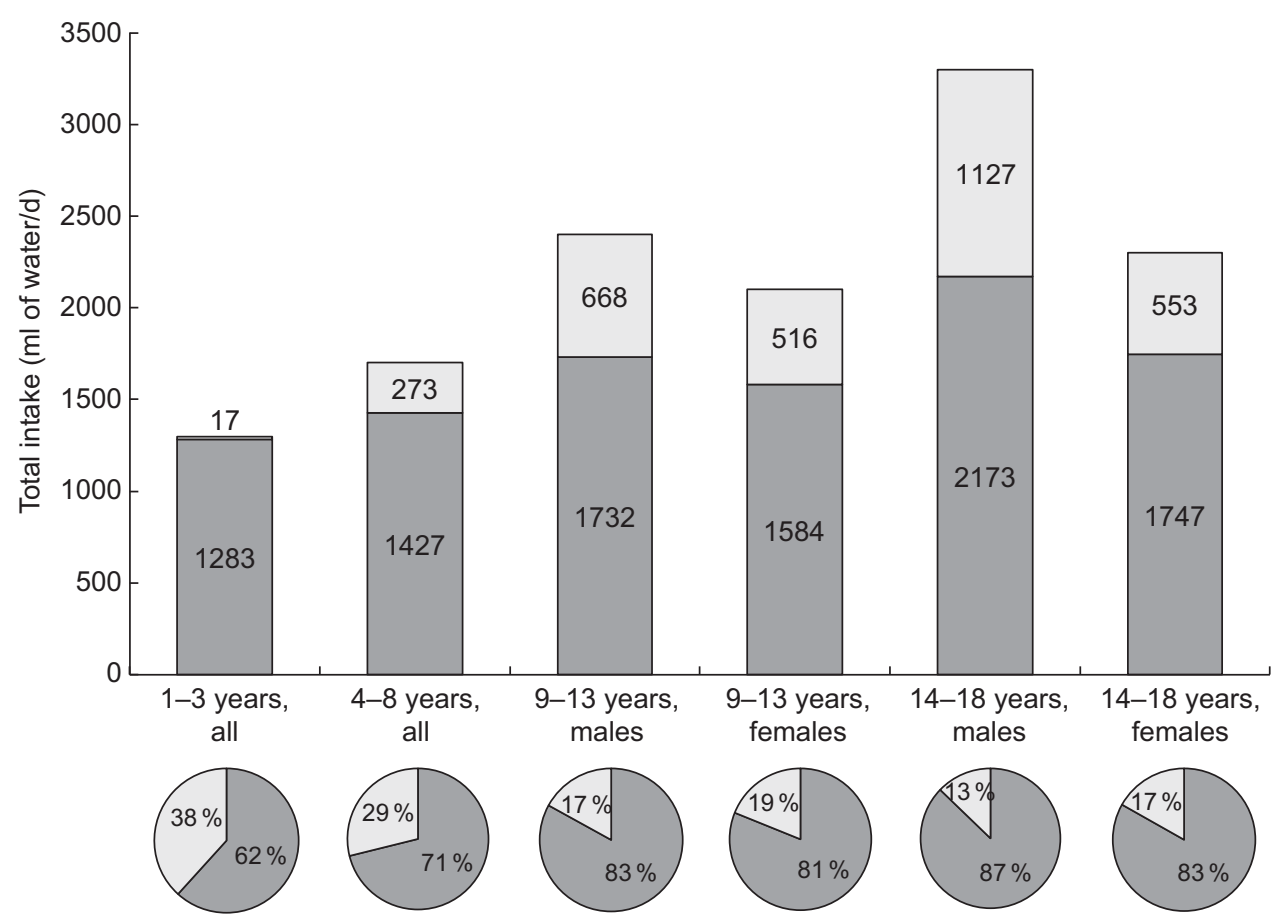

Fig. 2 Total daily water intake from all sources ( $\square$, consumed) by age group and gender in relation to the US Institute of Medicine recommendations ( $\square$, shortfall); children and adolescents aged $1-18$ years ( $n 6867)$, Mexican National Health and Nutrition Survey, 2012. The proportion of children who do $(\square)$ or do not meet $(\square)$ Institute of Medicine Dietary Reference Intakes is shown in the corresponding pie chart

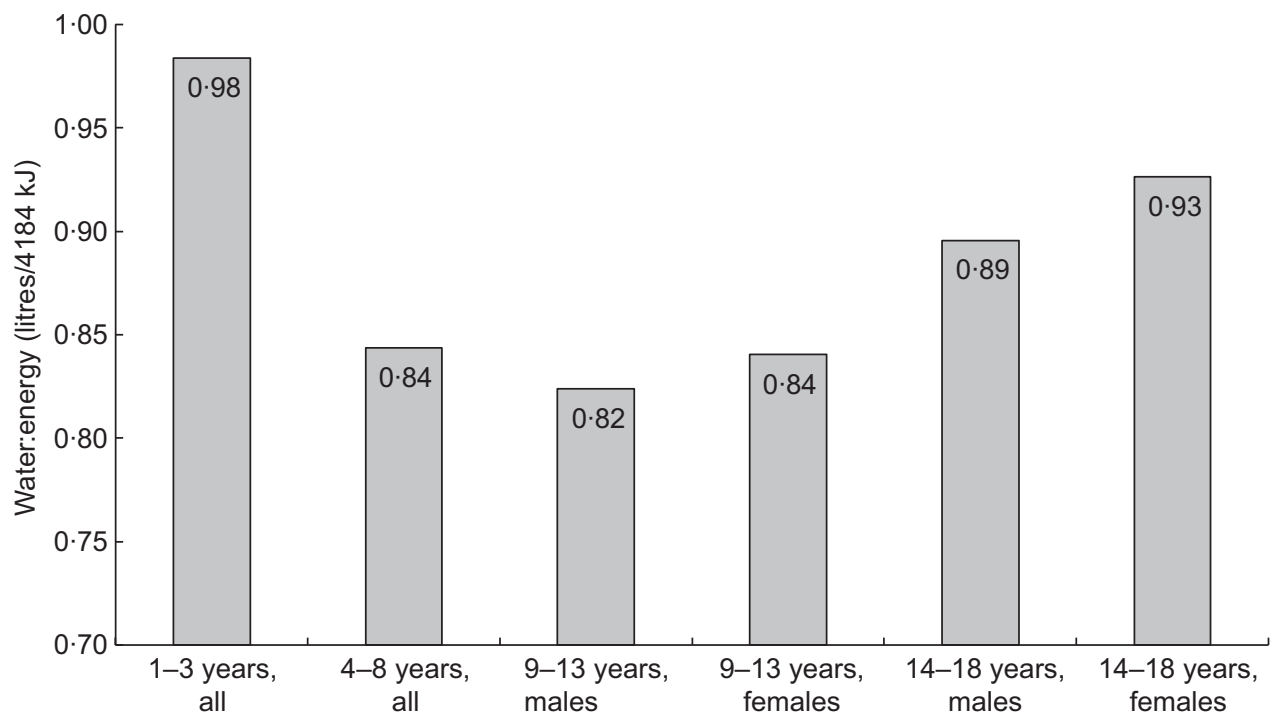

Fig. 3 Mean ratio of water to energy (litres/4184 kJ (1000 kcal)) by age and gender; children and adolescents aged 1-18 years ( $n$ 6867), Mexican National Health and Nutrition Survey, 2012

recommendations for total daily water ${ }^{(22)}$. The ratio of water to energy was $0.85-0.95$ litres/4184 kJ in these age groups. As was pointed out by Drewnowski et al. ${ }^{(22)}$, our results should also be interpreted cautiously. Although the mean of one $24 \mathrm{~h}$ recall should give a reasonable estimate of the mean intake at the population level ${ }^{(14,21)}$, the proportion of children below the IOM DRI might be overestimated due to under-reporting of water intake.
Adequate hydration and healthy beverage habits in Mexican children and adolescents should be encouraged in light of these results. In 2008, an expert committee developed the Beverage Consumption Recommendations for the Mexican Population, taking into account important factors such as the health benefits, risks and nutritional implications of beverage consumption $^{(4)}$. These guidelines were intended to inform consumers, health professionals and government officials of 
the importance of healthy beverage habits in the context of the high rates of overweight and obesity in Mexico ${ }^{(18,23,24)}$. Overweight and obesity has been increasing since 1999 among Mexican children and adolescents ${ }^{(25)}$. Our study showed that in 2012 the prevalence of overweight and obesity was $27.5 \%$, suggesting that lifestyle modifications that occur as children age might impact their weight status. Approximately, beverages accounted for from one-fifth to one-quarter of the total daily energy intake among the children in the present study. The top five beverage contributors to energy intake in our population of Mexican children and adolescents were flavoured milk beverages, caloric sweetened soda, high-fat milk, agua fresca (fruit water) and caloric coffee/tea. Importantly, older children and adolescents had a higher consumption of beverages with high energy but low nutritional value (i.e. caloric sweetened soda), whereas younger children had a higher proportion of caloric beverages with higher nutritional and energy value (i.e. high-fat milk). Beverage displacement changes towards more sweetened beverages have been previously documented in children in relation to weight management ${ }^{(26,27)}$. Overall, consumption of caloric sweetened beverages has been extensively linked with obesity and poor heath outcomes independently of energy intake, given their effect on satiety and insulin metabolism ${ }^{(28-30)}$. Given the nutritional and health implications associated with these beverages, the Beverage Consumption Recommendations for the Mexican Population encouraged the consumption of plain water as a first choice $(750-2000 \mathrm{ml} / \mathrm{d}$ ), followed by no/low calorie beverages with no sugar added and skimmed milk. The committee did not recommend any daily consumption of caloric sweetened beverages (including caloric soda, agua fresca, juice drinks and sweetened coffee/ tea), but rather an occasional consumption and small servings of these beverages ${ }^{(4)}$.

There are limitations to note regarding the present study. First, the NHNS 2012 is a cross-sectional observational data set and our analysis used self-reported intake data over a $24 \mathrm{~h}$ period. Self-reported intake might be affected by recall bias and also by reporting errors from the proxy recall in younger children (i.e. water and other beverages drank outside home might be missed). Even though total energy intake might be under-reported, our estimates seem to be in line with those found for similar age groups of children and adolescents in the USA ${ }^{(31)}$. However, recall of water intake might be even more problematic, especially in cases when the respondent drinks water unconsciously (i.e. drinking from a water fountain in the street or drinking from a glass that is constantly refilled at a restaurant). Given that for children and adolescents the ratio of within- to betweensubject variability is larger ${ }^{(32,33)}$, one day of dietary recall is not representative of the usual intake, so the percentage of children who fail to meet the DRI might be overestimated $^{(14,21)}$. Also, when comparing actual water intakes with $\mathrm{AI}$ at the individual level, there is a lot of variation depending of physical activity levels, health status and environment that needs to be taken into account ${ }^{(34,35)}$. Seasonal variations could also affect our results because the Mexican NHNS 2012 collected data from October through May. However, although water and liquid consumption is presumably higher over the summer months, children might not meet their daily needs because the requirements also increase in high-temperature environments. Still, we expect that the NHNS captures some of the seasonal variation by including data from different geographical regions - with a wide range of temperatures - across the country. DRI for total water are set up to help achieve an adequate hydration status but there is a much inter-individual variation to consider ${ }^{(2)}$. Our analysis did not consider these additional factors and just showed a crude estimate of actual total daily water intake and the difference with the recommended intake for the general population of children and adolescents. The main strength of this analysis is that we provided current unreported nationally representative data on water and beverage intake patterns among children and adolescents in Mexico.

The present study contributes valuable information for public policies and intervention efforts that aim to improve the hydration status and beverage habits of Mexican children. Our results come at the time when the government has instituted a 10\% tax in January 2014 on all beverages with added sugar as a way to reduce overweight and obesity and to encourage water consumption. Water intakes should be increased among children of all ages, especially among older children and adolescents who have more elevated requirements than younger children ${ }^{(12)}$. Although most children drink plain water on a daily basis, caloric sweetened beverages such as soda and agua fresca are currently major sources of total daily water especially among older children and adolescents. Public health efforts in Mexico should start by educating children on healthier beverage options for adequate hydration, and also by increasing awareness about food sources with higher water contents such as fruits and vegetables.

\section{Conclusion}

Our study is one of the first to carefully explore current water consumption patterns among Mexican children and adolescents. Plain water still contributes the greatest proportion to daily water intake from beverages. However, caloric beverages are currently major sources of water especially among older children and adolescents. Although total daily water intakes remain below DRI levels in all age groups, the study identifies key age and gender groups that will benefit from targeted interventions that aim to improve the nutritional and hydration status of children and adolescents in Mexico.

\section{Acknowledgements}

Acknowledgements: The authors thank Phil Bardsley and Fabricio Campirano for exceptional assistance with the 
data management and programming, Tom Swasey for graphic support and Frances L. Dancy for administrative assistance. Financial support: This study was supported by Nestlé Waters MT, Paris, France. Nestlé had no role in the design, analysis or writing of this article. Conflict of interest: B.M.P. and S.B. were collaborators on a grant from the National Institute of Public Health in Mexico to fund a water randomized controlled trial (Danone Waters Research Center). B.M.P. received travel funding to present beverage patterns and health research at the British Nutrition Society (Danone Waters Research); and was a collaborator on a sugar-sweetened beverage randomized controlled trial funded by Nestlé Waters USA. C.P. has no conflicts of interest of any type with respect to this manuscript. The authors alone are responsible for the content and writing of the paper. Authorship: C.P., S.B. and B.M.P. designed the research (project conception, development of overall research plan and study oversight); C.P., S.B. and B.M.P. conducted the research (hands-on conduct of the experiments and data collection); C.P. and B.MP. analysed the data or performed statistical analysis; C.P. and B.M.P. wrote and revised the manuscript; C.P., S.B. and B.M.P. had primary responsibility and approved the final content. Ethics of human subject participation: The NHNS 2012 was conducted according to the guidelines laid down in the Declaration of Helsinki and the survey protocol was revised and approved by the Ethics Committee of the Mexican National Institute of Public Health. Informed consent was obtained from each participant or participant's parent/ guardian (assent was obtained for children $\geq 10$ years).

\section{Supplementary material}

To view supplementary material for this article, please visit http://dx.doi.org/10.1017/S1368980014000998

\section{References}

1. Daniels MC \& Popkin BM (2010) Impact of water intake on energy intake and weight status: a systematic review. Nutr Rev 68, 505-521.

2. Popkin BM, D'Anci KE \& Rosenberg IH (2010) Water, hydration, and health. Nutr Rev 68, 439-458.

3. Popkin BM, Armstrong LE, Bray GM et al. (2006) A new proposed guidance system for beverage consumption in the United States. Am J Clin Nutr 83, 529-542.

4. Rivera JA, Muñoz-Hernández $\mathrm{O}$, Rosas-Peralta $\mathrm{M}$ et al. (2008) Consumo de bebidas para una vida saludable: recomendaciones para la población mexicana. Salud Publica Mex 50, 173-195.

5. Barquera S, Campirano F, Bonvecchio A et al. (2010) Caloric beverage consumption patterns in Mexican children. Nutr J 9, 47 .

6. Barquera S, Hernandez-Barrera L, Tolentino ML et al. (2008) Energy intake from beverages is increasing among Mexican adolescents and adults. J Nutr 138, 2454-2461.

7. Oria M \& Sawyer K (2007) Joint US-Mexico Workshop on Preventing Obesity in Children and Youth of Mexican
Origin: Summary. Washington, DC: National Academies Press.

8. Manz F, Wentz A \& Sichert-Hellert W (2002) The most essential nutrient: defining the adequate intake of water. J Pediatr 141, 587-592.

9. Astudillo O (2013) Country in focus: Mexico's growing obesity problem. Lancet Diabetes Endocrinol 2, 15-16.

10. Flannery NP (2013) Mexico may make Coca-Cola give up cane sugar. Forbes, 11 July 2013. http://www.forbes. com/sites/nathanielparishflannery/2013/11/07/in-responseto-new-soda-tax-coca-cola-bottler-considers-switch-from-sugarto-high-fructose-corn-syrup-in-mexico/ (accessed May 2014).

11. Agostoni CV, Bresson JL, Fairweather-Tait S et al. (2010) Scientific opinion on dietary reference values for water. EFSA J 8, 1459.

12. Institute of Medicine (2004) Dietary Reference Intakes for Water, Potassium, Sodium, Chloride, and Sulfate. Washington, DC: National Academies Press.

13. Romero-Martínez M, Shamah-Levy T, Franco-Núñez A et al. (2013) Encuesta Nacional de Salud y Nutrición 2012: diseño y cobertura. Salud Publica Mex 55, Suppl. 2, S332-S340.

14. Gibson RS (editor) (2005) Measuring food consumption of individuals. In Principles of Nutritional Assessment, 2nd ed., pp. 41-64. New York: Oxford University Press.

15. Batis C, Hernandez-Barrera L, Barquera S et al. (2011) Food acculturation drives dietary differences among Mexicans, Mexican Americans, and Non-Hispanic Whites. J Nutr 141, 1898-1906.

16. US Department of Agriculture, Agricultural Research Service, Nutrient Data Laboratory (2013) National Nutrient Database for Standard Reference, Release 26. Nutrient Data Laboratory Home Page. http://www.ars.usda.gov/ba/ bhnrc/ndl (accessed November 2013).

17. Gutiérrez JP (2013) Clasificación socioeconómica de los hogares en la ENSANUT 2012. Salud Publica Mex 55, Suppl. 2, S341-S346.

18. Barquera S, Campos-Nonato I, Hernández-Barrera L et al. (2013) Prevalencia de obesidad en adultos mexicanos, ENSANUT 2012. Salud Publica Mex 55, Suppl. 2, S151-S160.

19. De Onis M, Onyango AW, Borghi E et al. (2007) Development of a WHO growth reference for school-aged children and adolescents. Bull World Health Organ 85, 660-667.

20. WHO Muticentre Growth Reference Study Group (2006) WHO Child Growth Standards based on length/height, weight and age. Acta Paediatr Suppl 450, 76-85.

21. Carriquiry AL (2003) Estimation of usual intake distributions of nutrients and foods. J Nutr 133, issue 2, 601S-608S.

22. Drewnowski A, Rehm CD \& Constant F (2013) Water and beverage consumption among children age $4-13$ y in the United States: analyses of 2005-2010 NHANES data. Nutr J 12, 85 .

23. Rtveladze K, Marsh T, Barquera S et al. (2014) Obesity prevalence in Mexico: impact on health and economic burden. Public Health Nutr 17, 233-239.

24. Rivera JA, Barquera S, Campirano F et al. (2002) Epidemiological and nutritional transition in Mexico: rapid increase of non-communicable chronic diseases and obesity. Public Health Nutr 5, 113-122.

25. Olaiz G (2006) Encuesta Nacional de Salud y Nutrición 2006. Cuernavaca: Instituto Nacional de Salud Pública.

26. Oza-Frank R, Zavodny M \& Cunningham SA (2012) Beverage displacement between elementary and middle school, 2004-2007. J Acad Nutr Diet 112, 1390-1396.

27. O'Connor TM, Yang S-J \& Nicklas TA (2006) Beverage intake among preschool children and its effect on weight status. Pediatrics 118, e1010-e1018.

28. Malik VS, Pan A \& Willett WC et al. (2013) Sugar-sweetened beverages and weight gain in children and adults: a systematic review and meta-analysis. Am J Clin Nutr 98, 1084-1102. 
29. de Ruyter JC, Olthof MR \& Seidell JC et al. (2012) A trial of sugar-free or sugar-sweetened beverages and body weight in children. $N$ Engl J Med 367, 1397-1406.

30. Ebbeling CB, Feldman HA \& Chomitz VR et al. (2012) A randomized trial of sugar-sweetened beverages and adolescent body weight. $N$ Engl J Med 367, 1407-1416.

31. Ervin RB \& Ogden CL (2013) Trends in Intake of Energy and Macronutrients in Children and Adolescents from 1999-2000 through 2009-2010. NCHS Data Brief no. 113. Hyattsville, MD: National Center for Health Statistics.
32. Livingstone MBE \& Robson PJ (2000) Measurement of dietary intake in children. Proc Nutr Soc 59, 279-293.

33. Livingstone MBE, Robson PJ \& Wallace JMW (2004) Issues in dietary intake assessment of children and adolescents. $\mathrm{Br}$ J Nutr 92, Suppl. 2, S213-S222.

34. Campbell SM (2007) Hydration needs throughout the lifespan. J Am Coll Nutr 26, 5 Suppl, 585S-587S.

35. Jéquier E \& Constant F (2009) Water as an essential nutrient: the physiological basis of hydration. Eur J Clin Nutr $\mathbf{6 4}$, $115-123$. 